\title{
Impact of water renewal on the residual effect of larvicides in the control of Aedes aegypti
}

\author{
Ricardo José Soares Pontes ${ }^{1 /+}$, Fábio Fernandes Dantas Filho ${ }^{2}$, Carlos Henrique Morais de Alencar ${ }^{1}$, \\ Ana Cláudia Ferreira Regazzi ${ }^{3}$, Luciano Pamplona de Góes Cavalcanti ${ }^{1}$, \\ Alberto Novaes Ramos Jr ${ }^{1}$, José Wellington de Oliveira Lima ${ }^{3,4}$
}

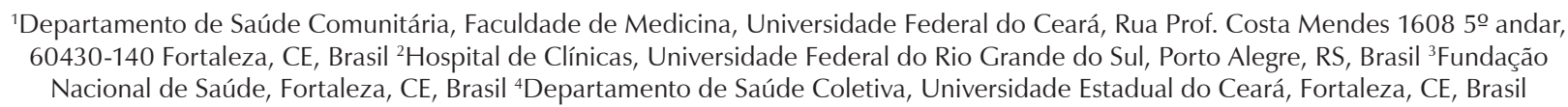

This study was carried out to evaluate the residual effect of three larvicides under laboratory conditions for 100 days in Aedes aegypti. The larval mortality rate was measured without water renewal or with daily water renewal (80\%). With temephos, there was $100 \%$ mortality in both groups until the 70th day. In the Bacillus thuringiensis israelensis (Bti)-WDG test, there was no difference during the first 20 days. With Bti-G, without water renewal, mortality was sustained above $90 \%$ for up to 35 days. The second experiment (with water renewal) reduced the mortality to below $90 \%$ after the first 20 days. When renewed water was provided, the residual effect was significantly lower for all larvicides.

Key words: Aedes - dengue - insect control - insecticides - organophosphate -Bacillus thuringiensis

Aedes aegypti is the main vector for dengue and urban yellow fever. For more than two decades, the main form of control has been the use of insecticides. The water renewal method has previously been used to assess the residual effect of the inseticide temephos in field and laboratory experiments (Chadee 1984). However, the majority of experiments carried out to measure the residual power of both chemical and biological insecticides did not take into consideration the effect of daily water renewal in domestic containers (Fortin et al. 1987, Pinheiro $\&$ Tadei 2002, Lima et al. 2005). Several tests have been conducted to observe the residual power of larvicides with partial or complete water replacement (Mulla et al. 2004, Thavara et al. 2005, Tawatsin et al. 2007). However, this procedure did not show the current situation in terms of dynamic water replacement in the tanks present in Brazil (Pontes et al. 2005). This can modify the real period of efficacy of the insecticides and thus interfere with the quality of Brazilian Ae. aegypti control programs based on this strategy. Our goal is to evaluate the impact of water renewal on the duration of the residual effect of three larvicides used in Brazilian Ae. aegypti control programs, under laboratory conditions.

We carried out a longitudinal study in order to estimate the best-controlled conditions for larval survival over time. The tests were carried out at the Entomology Laboratory of the Department of Community Health of the Federal University of Ceará, Brazil. The impact of water renewal was tested with three larvicides: teme-

+Corresponding author: rjpontes@fortalnet.com.br Received 23 June 2009

Accepted 3 February 2010 phos [0.1 g/L] (organophosphate larvicide) and Bacillus thuringiensis israelensis (Bti) - serotype H14, in two forms: water dispersible granulate $3.000 \mathrm{ITU} / \mathrm{mg}[0.02$ $\mathrm{g} / \mathrm{L}]$ and Granulated $200 \mathrm{ITU} / \mathrm{mg}$ [0.002 g/L]. All larvicides were provided by the dengue control program and were all within their validity period. The Rockefeller strain of Ae. aegypti was chosen based a susceptibility pattern, courtesy of the Research Center of Natural Products, Federal University of Rio de Janeiro.

Ae. aegypti late third instar larvae (L3) were used in all assays. The tests were carried out in $1.000 \mathrm{~mL}$ beakers (WHO 2005). Larvicides were weighed on a precision scale with an accuracy of three decimal places. Four different beakers were used, containing $1.000 \mathrm{~mL}$ solution of the respective insecticide and three different beakers containing $1.000 \mathrm{~mL}$ of water were used as a control solution.

First, the beakers were filled up to the $1.000 \mathrm{~mL}$ level and only the water that naturally evaporated was restored. Next, $80 \%$ of the water in the beaker was removed using a hose and the water was replaced daily to simulate the average use of a residential household in Brazil. Every five days, 25 larvae were introduced to each beaker, so that 100 larvae were exposed to the larvicides and another 75 served as a control. Mortality was scored 24 $\mathrm{h}$ after the larvae had been placed in the container. Initially, dead larvae were directly visualised, removed and counted; subsequently, all living larvae were counted. This procedure was performed using plastic pipettes for 100 consecutive days.

We used the mortality ratio (MR) as a quantitative indicator of the relative larval mortality among the different larvicides to evaluate and analyse with greater accuracy the performance of the products related to the renewal or non-renewal of water in the containers. We defined MR as a ratio between the MR, probability of 


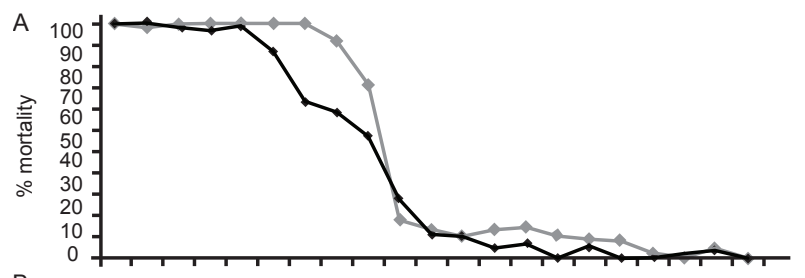

B

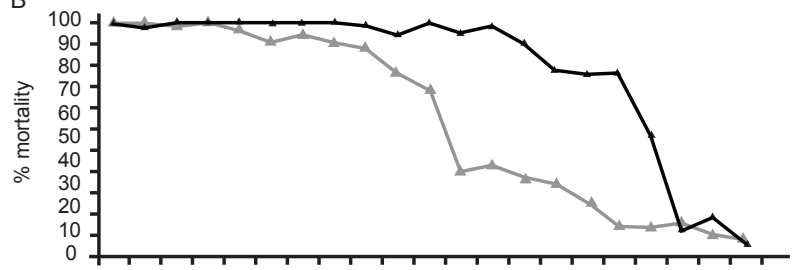

C

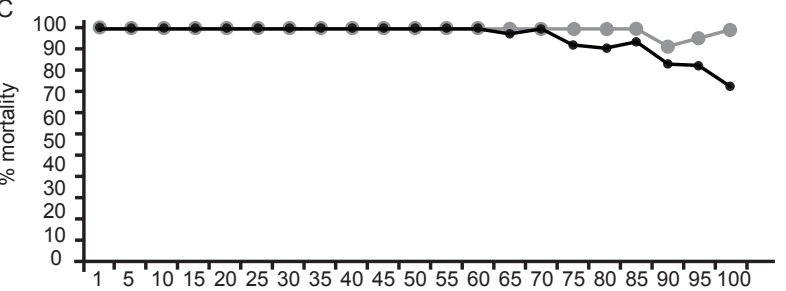

Mortality proportion of Aedes aegypti larvae of under effect of larvicides Bti-G (A), Bacillus thuringiensis israelensis (Bti)-WDG (B) and temephos (C) with and without renewal of water.

mortality or simple mortality and the number of larvae exposed to each of the larvicides. This indicator has been used previously for the evaluation of mosquito larvicides and is numerically equivalent to relative risk (RR) (Rothman 2002, Pontes et al. 2005, Medronho et al. 2008). All information obtained was computer analysed using the Epi Info 6.04d.

In the experiment using the temephos larvicide (Figure) there was no difference in larval mortality in the experiments with or without water renewal (100\% mortality for both) until the 70th day. Thereafter, larval mortality was higher in the experiment without renewal, as compared to the experiment with water renewal.

The results of the experiment without water renewal showed continuation of the proportion of larval mortality above $90 \%$ until the completion of the experiment (100 days), the best performance obtained in our study. In the experiment with water renewal, mortality was observed above the threshold of $90 \%$ until day 85 . However, the proportion declined afterwards, falling below this threshold and reaching 74\% mortality on the 100th day. Larval mortality in the control group did not exceed $3.45 \%$.

The mortality variation was statistically significant (Table I) between the experiment with or without renewal of water. The extremes were between $6 \%(\mathrm{MR}=1.06$, 95\% CI: $1.01-1.12)$ and 35\% (MR $=1.35,95 \% \mathrm{CI}: 1.20-$ 1.52 ) in the period between 75-100 days of the experiment, i.e., there was lower proportional larval mortality in the experiment with water renewal, reaching $35 \%$ on the 100th day of the experiment.

In the experiment using the Bti-WDG larvicide (Figure) there was no difference in larval mortality in the experiments with or without water renewal (100\% mortali- ty of both) until the 20th day. Thereafter, larval mortality was higher in the experiment without renewal compared to the experiment with water renewal.

The results of the experiment without water renewal showed stable larval mortality above 90\% (taken as the threshold for our best result) until the 65 th day of experiment and was reduced to $79 \%$ on the 80 th day and $52 \%$ on the 85 th (and to less than 20\% afterwards). In comparison, the results of the experiment with water renewal larval mortality fell to below $90 \%$ after 35 days, remaining above $70 \%$ only until the 50 th day of the experiment (falling to values between $31-39 \%$ by the 70 th day and levels below $25 \%$ thereafter). Larval mortality in the control group did not exceed $3.45 \%$.

The variation of mortality between the experiment with and without water renewal was statistically significant (Table II) between the extremes of 5\% (MR = 1.05, 95\% CI: $1.01-1.10)$ and $168 \%(\mathrm{MR}=2.68,95 \% \mathrm{CI}$ : $2.02-3.54)$ in the period between the 25-70th days of the experiment (we did a relative comparison between the two experiments after 70 days because they both had very low larval mortality). As such, there was lower larval mortality in the experiment with water renewal at a rate that reached $168 \%$ (between the $25-70$ th days of the experiment).

In the experiment using the Bti-G larvicide (Figure), no difference was observed in larval mortality with or without water renewal (100\% mortality for both) until the 20th day. Thereafter, larval mortality was higher in the experiment without water renewal, although a level above $90 \%$ only was maintained through the first 35 days, falling to $74 \%$ after 40 days and thereafter to a very low subsequent mortality of under $20 \%$. In comparison, the results of the experiment with water renewal reduced larval mortality to below $90 \%$ after 20 days (falling further to $52 \%$ at 40 days and below $25 \%$ thereafter). Larval mortality in the control group did not exceed $3.45 \%$.

Mortality variation was statistically significant (Table III) in the experiment without water renewal between the extremes of $14 \%(\mathrm{MR}=1.14,95 \% \mathrm{CI}: 1.06-1.22)$ and $50 \%$ $(\mathrm{MR}=1.50,95 \% \mathrm{CI}: 1.27-1.76)$ in the period between the 25-40th days (we compared the 2 sets of experimental data after 40 days because the larval mortality rates were still very low). In other words, larval mortality was lower in the experiment with water renewal at a rate that reached $50 \%$ (between 25-40th days of the experiment).

Our data show that water renewal in the treated receptacles presented a different relation of larval mortality when exposed to temephos compared to Bti. Temephos is better in maintaining high mortality of larvae in containers. Granulated commercial Bti-treated samples, in both formulations, presented inferior mortality with daily water renewal, as is commonly found in households in Brazil. In the field, water in storage containers is renewed daily and this fact is rarely taken into consideration in the diverse studies assessing the residual effect of insecticides against Ae. aegypti.

Historically, temephos has been used as a means of controlling mosquitoes through its residual effect (Chadee 1984). In Thailand, the tablet form of this larvicide, used at the dose of one tablet/50 L of water in ceramic repositories of approximately $200 \mathrm{~L}$, provided excellent con- 
trol for approximately 112 days without water renewal. In deposits where $50 \%$ of water was renewed each week, excellent control lasted for 90 days (Mulla et al. 2004).

In Brazil, a tablet form of Bti controlled Ae. aegypti larvae for between 40-54 days in the shade. This fact does not represent the conditions found for some water containers in field. Exposure to the sun resulted in activity control from 13-35 days after a single intervention with larvicide (Melo-Santos et al. 2001). The residual effect of the Bti formula used had a greater action in unused wells, causing a reduction of more than $80 \%$ in the formation of pupae for 17 days after the initial treatment (Gunasekaran et al. 2004).

Larvae treated with Bti products had a mortality rate of $95 \%$ for up to 45 days in Brazil (Lima et al. 2005). After that period, its efficiency fell abruptly, reaching a mortality of only $24 \%$ at 66 days after the start of the test. Moreover, a second formula led to a higher mortality rate of over $95 \%$ for up to 101 days, when the experiment was interrupted (Lima et al. 2005).

These differences may interfere with the efficacy and cost-effectiveness of the dengue fever control program, with serious consequences on the occurrence of dengue fever epidemics. It has been clearly demonstrated that the renewal of water in water containers directly interferes with the persistence of the residual effect of larvicides, reducing the mortality period.

In water containers treated with temephos, there was a slight fall only 75 days after its application, demonstrating a controlled dissolution. This period is important to plan the average length of time between home visits for water treatment. For example, $1 \%$ temephos in grains of sand added to water containers had acceptable results for 28-42 days under field conditions (Chadee 1984). According to Lee and Winita (1993), ceramic containers treated with temephos lead to $100 \%$ mortality of Aedes albopictus for up to 91 days after treatment (Lee \& Winita 1993). Similar results were found by Chen and Lee (2006), with a residual effect of 105 days and $100 \%$ of mortality of larvae, at the dose recommended by the manufacturer (Chen \& Lee 2006).

In Thailand, temephos' efficiency was tested in grains of sand in the field to combat Ae. aegypti. Using enamelled ceramic water containers with water renewal, $100 \%$ mortality rate was observed for over six months (Mulla et al. 2004). Thavara et al. (2004) showed that a simple application of temephos grains may promote satisfactory control of Ae. aegypti in containers for a period of up to three months in the field, with normal water use (Thavara et al. 2004).

However, in laboratory tests in Peru, the temephos larvicide maintained its effectiveness for the first 42 days, after which there was a reduction in mortality of $11 \%$ per week, falling to a mortality rate of only $37.4 \%$ in the 14th week, which would lead to a re-colonisation of these containers by Ae. aegypti (Palomino et al. 2006).

In a field study in Brazil, focal treatment with temephos was evaluated in two distinct areas, showing that there was no relevant impact of the application of temephos on the prevalence of Ae. aegypti larvae. The transitory effectiveness of the temephos was approximately

TABLE I

Average mortality proportion of the presentations of commercial larvicide temephos used with and without renewal of water, relative risk (CI 95\%)

\begin{tabular}{lcccc}
\hline Days after exposure & $\begin{array}{c}\text { Mortality proportion (a) } \\
\text { without renewal }\end{array}$ & $\begin{array}{c}\text { Mortality proportion (b) } \\
\text { with renewal }\end{array}$ & Mortality ratio (a/b) & Mortality ratio CI-95\% \\
\hline 1 & 100 & 100 & 1.00 & - \\
5 & 100 & 100 & 1.00 & - \\
10 & 100 & 100 & 1.00 & - \\
15 & 100 & 100 & 1.00 & - \\
20 & 100 & 100 & 1.00 & - \\
25 & 100 & 100 & 1.00 & - \\
30 & 100 & 100 & 1.00 & - \\
35 & 100 & 100 & 1.00 & - \\
40 & 100 & 100 & 1.00 & - \\
45 & 100 & 100 & 1.00 & - \\
50 & 100 & 100 & 1.00 & - \\
55 & 100 & 100 & 1.00 & - \\
60 & 100 & 100 & 1.00 & - \\
65 & 100 & 99 & 1.01 & - \\
70 & 100 & 100 & 1.00 & - \\
75 & 100 & 93 & 1.10 & 1.08 \\
80 & 100 & 91 & 1.06 & $1.01-1.17$ \\
85 & 100 & 94 & 1.10 & 1.12 \\
90 & 92 & 84 & 1.35 & $1.05-1.27$ \\
95 & 96 & 83 & $1.20-1.52$ \\
\hline
\end{tabular}


TABLE II

Average mortality proportion of the presentations of commercial larvicide Bacillus thuringiensis israelensis-wdg used with and without renewal of water, relative risk (CI 95\%)

\begin{tabular}{|c|c|c|c|c|}
\hline Days after exposure & $\begin{array}{c}\text { Mortality proportion (a) } \\
\text { without renewal }\end{array}$ & $\begin{array}{l}\text { Mortality proportion (b) } \\
\text { with renewal }\end{array}$ & Mortality ratio $(\mathrm{a} / \mathrm{b})$ & Mortality ratio CI-95\% \\
\hline 1 & 100 & 100 & 1.00 & - \\
\hline 5 & 100 & 100 & 1.00 & - \\
\hline 10 & 100 & 99 & 1.01 & $0.99-1.03$ \\
\hline 15 & 100 & 100 & 1.00 & - \\
\hline 20 & 100 & 97 & 1.03 & $1.00-1.07$ \\
\hline 25 & 100 & 92 & 1.09 & $1.03-1.15$ \\
\hline 30 & 100 & 95 & 1.05 & $1.01-1.10$ \\
\hline 35 & 100 & 92 & 1.09 & $1.03-1.15$ \\
\hline 40 & 99 & 89 & 1.11 & $1.04-1.20$ \\
\hline 45 & 95 & 79 & 1.20 & $1.08-1.34$ \\
\hline 50 & 100 & 71 & 1.41 & $1.24-1.60$ \\
\hline 55 & 96 & 36 & 2.67 & $2.05-3.47$ \\
\hline 60 & 99 & 39 & 2.54 & $1.99-3.25$ \\
\hline 65 & 91 & 34 & 2.68 & $2.02-3.54$ \\
\hline 70 & 80 & 31 & 2.58 & $1.90-3.51$ \\
\hline 75 & 78 & 23 & 3.39 & $2.33-4.93$ \\
\hline 80 & 79 & 13 & 6.08 & $3.62-10.19$ \\
\hline 85 & 52 & 12 & 4.33 & $2.47-7.61$ \\
\hline 90 & 11 & 14 & 0.79 & $0.38-1.65$ \\
\hline 95 & 16 & 9 & 1.78 & $0.82-3.83$ \\
\hline 100 & 5 & 7 & 0.71 & $0.23-2.18$ \\
\hline
\end{tabular}

\section{TABLE III}

Average mortality proportion of the presentations of commercial larvicide Bacillus thuringiensis israelensis-g used with and without renewal of water, relative risk (CI 95\%)

\begin{tabular}{lcccc}
\hline Days after exposure & $\begin{array}{c}\text { Mortality proportion (a) } \\
\text { without renewal }\end{array}$ & $\begin{array}{c}\text { Mortality proportion (b) } \\
\text { with renewal }\end{array}$ & Mortality ratio (a/b) & Mortality ratio CI-95\% \\
\hline 1 & 100 & 100 & 1.00 & - \\
5 & 100 & 100 & 1.00 & - \\
10 & 100 & 99 & 1.01 & $0.99-1.03$ \\
15 & 100 & 97 & 1.03 & $1.00-1.07$ \\
20 & 100 & 99 & 1.01 & $0.99-1.03$ \\
25 & 100 & 88 & 1.14 & $1.06-1.22$ \\
30 & 100 & 67 & 1.49 & $1.30-1.71$ \\
35 & 93 & 62 & 1.50 & $1.27-1.76$ \\
40 & 74 & 52 & 1.42 & $1.14-1.78$ \\
45 & 16 & 25 & 0.64 & $0.36-1.12$ \\
50 & 12 & 10 & 1.20 & $0.54-2.65$ \\
55 & 9 & 9 & 1.00 & $0.41-2.41$ \\
60 & 12 & 4 & 3.00 & $1.00-8.99$ \\
65 & 13 & 6 & 2.17 & $0.86-5.47$ \\
70 & 9 & 0 & 0.00 & $0.00-0.00$ \\
85 & 8 & 5 & 1.60 & $0.54-4.72$ \\
85 & 7 & 0 & 0.00 & $0.00-0.00$ \\
90 & 2 & 0 & 0.00 & $0.00-0.00$ \\
100 & 0 & 2 & 0.00 & $0.00-0.00$ \\
\hline
\end{tabular}


21 days. The eventual water renewal and the consequent dilution in the fixed containers led to the inefficacy of this treatment (Donalisio et al. 2002).

Our data reinforce the evidence that water renewal in domestic containers can have a negative influence on the residual effect of larvicides used in vector control programs, especially when using Bti.

\section{REFERENCES}

Chadee DD 1984. An evaluation of temephos in water drums in Trinidad, W.I. Mosq News 44: 51-53.

Chen CD, Lee HL 2006. Laboratory bioefficacy of CREEK 1.0G (temephos) against Aedes (Stegomyia) aegypti (Linnaeus) larvae. Trop Biomed 23: 220-223.

Donalisio MRC, Leite OF, Mayo RC, Alves MJCP, Souza A, Rangel O Andrade VR, Oliveira SS, Matias VLM 2002. Use of temephos for control of field population of Aedes aegypti in Americana, São Paulo, Brazil. Dengue Bull 26: 173-177.

Fortin C, Maire A, Leclair R 1987. The residual effect of temephos (Abate 4-E) on nontarget communities. J Am Mosq Control Assoc 3: 282-288.

Gunasekaran K, Doss PS, Vaidyanathan K 2004. Laboratory and field evaluation of Teknar HP-D, a biolarvicidal formulation of Bacillus thuringiensis spp israelensis, against mosquito vectors. Acta Trop 92: 109-118.

Lee HL, Winita R 1993. Laboratory and field evaluation of permethrin against Aedes (Stegomyia) albopictus (Skuse) larvae. Mosq-Borne Diseases Bull 10: 77-82.

Lima JB, de Melo NV, Valle D 2005. Residual effect of two Bacillus thuringiensis var. israelensis products assayed against Aedes aegypti (Diptera: Culicidae) in laboratory and outdoors at Rio de Janeiro, Brazil. Rev Inst Med Trop Sao Paulo 47: 125-130.

Medronho RA, Bloch KV, Luiz RR, Werneck GL 2008. Epidemiologia, Atheneu, Rio de Janeiro, $790 \mathrm{pp}$

Melo-Santos MA, Sanches EG, de Jesus FJ, Regis L 2001. Evaluation of a new tablet formulation based on Bacillus thuringiensis Soro- var israelensis for larvicidal control of Aedes aegypti. Mem Inst Oswaldo Cruz 96: 859-860.

Mulla MS, Thavara U, Tawatsin A, Chompoosri J 2004. Procedures for the evaluation of field efficacy of slow-release formulations of larvicides against Aedes aegypti in water-storage containers. J Am Mosq Control Assoc 20: 64-73.

Palomino MS, Solari L, León WC, Vega RH, Vergaray MC, Cubillas L, Mosqueda RC, García NA 2006. Evaluación del efecto residual del temephos en larvas de Aedes aegypti en Lima, Peru. Rev Peru Med Exp Salud Publica 23: 158-162.

Pinheiro VC, Tadei WP 2002. Evaluation of the residual effect of temephos on Aedes aegypti (Diptera: Culicidae) larvae in artificial containers in Manaus, Amazonas state, Brazil. Cad Saude Publica 18: 1529-1536.

Pontes RJ, Regazzi AC, Lima JW, Kerr-Pontes LR 2005. Efeito residual de apresentações comerciais dos larvicidas temefos e Bacillus thuringiensis israelensis sobre larvas de Aedes aegypti em recipientes com renovação de água. Rev Soc Bras Med Trop 38: 316-321.

Rothman KJ 2002. Epidemiology: an introduction, Oxford, New York, 240 pp.

Tawatsin A, Thavara U, Chompoosri J, Bhakdeenuan P, Asavadachanukorn P 2007. Larvicidal efficacy of new formulations of temephos in non-woven sachets against larvae of Aedes aegypti (L.) (Diptera: Culicidae) in water-storage containers. Southeast Asian J Trop Med Public Health 38: 641-645.

Thavara U, Tawatsin A, Kong-Ngamsuk W, Mulla MS 2004. Efficacy and longevity of a new formulation of temephos larvicide tested in village-scale trials against larval Aedes aegypti in water-storage containers. J Am Mosq Control Assoc 20: 176-182.

Thavara U, Tawatsin A, Srithommarat R, Zaim M, Mulla MS 2005. Sequential release and residual activity of temephos applied as sand granules to water-storage jars for the control of Aedes aegypti larvae (Diptera: Culicidae). J Vector Ecol 30: 62-72.

WHO - World Health Organization 2005. Guidelines for laboratory and field testing of mosquito larvicides. Available from: http://whqlibdoc.who.int/hq/2005/WHO_CDS_WHOPES GCDPP 2005.13.pdf. 